Journal of Environmental Science and Public Health

doi: $10.26502 /$ jesph. 96120054

Volume 3, Issue 2

Review Article

\title{
Challenges and Improvement Opportunities for Accra City MSWM System
}

\author{
Sylvia Adipah* \\ Department of Environmental Engineering and Science, Chongqing University, Chongqing, China \\ "Corresponding Author: Sylvia Adipah, Department of Environmental Engineering and Science, Chongqing \\ University, Chongqing 400044, China, E-mail: fransil351@yahoo.com
}

Received: 21 December 2018; Accepted: 20 March 2019; Published: 02 April 2019

\begin{abstract}
This paper is devoted to explain and understand the main problems and challenges in some elements of Municipal solid waste system in Accra City. It focus will be in management, authorities, functionality, processes, equipments and infrastructures, public awareness and participation as well as to present the lessons can be taken from Chongqing city MSWM system, and show opportunities and perspectives for Accra City MSWM system's improvement.
\end{abstract}

Keywords: MSWM system; Disposal methods; Accra city

\section{Introduction}

\subsection{Challenges for accra city MSWM system}

1.1.1 Authorities and institutional performance: Ghana's approach to waste management seems to regard waste as a problem that can be resolved with just funds and logistics. This explains why stakeholders in the waste sector regard the scarcity of funds and logistics as the greatest obstacles to waste management in the country. No doubt, money and equipment are essential for the day-to-day organisation of waste management activities, but the human resource factor is also critically important for the success of municipal waste management projects. The data gathered for this study show that, apart from finance and logistics, the waste problem facing Ghana cities is also critically related to the shortage of qualified personnel to carry out various tasks. In Ghana, the shortage of staff emerged as factors militating against efforts to provide waste management services. The Ministry of solid waste 
department admitted that their department was seriously understaffed and lacked key personnel in engineering, administration, finance and environmental health, a situation that makes it difficult for them to operate on a full scale. Due to the lack of engineers, it becomes difficult for municipal waste departments in the country to gain professional advice on such things as the suitability of equipment and the sitting, design, construction and maintenance of waste disposal facilities.

Furthermore, it emerged from interviews with the waste departments in the city that they lack researchers among their staff to investigate issues relating to waste management such as the types and quantities of waste generated, their sources and characteristics. As a result, waste departments in the country lack the necessary data to facilitate the planning and organisation of waste management. Besides, the lack of funds for waste management in the city is also linked to the shortage of qualified finance and accounting staff who will identify local sources of tax revenue, fix tax rates and employ creative measures to mobilise revenue for urban finance. From the data gathered, other professionals who are lacking in the waste sector include environmental health personnel, administrators and legal and security personnel to help with the enforcement of existing by-laws on waste management. Like other public institutions in the country, the waste department is, therefore, suffering from the situation where poor conditions of service make jobs there unattractive especially to well-qualified and technical staff. Recognised by the authorities and from the public questionnaire in Accra City, it's a fact that the dissemination of those formal documents and the information disclosure practices between the authorities and waste generators and other stakeholders, leaves a lot to be desired. Waste generators have knowledge limitations regarding MSW matters and it is the role of the authorities to create the proper environment to change the current situation. Also lacking in law and regulation enforcement may be considered as a cause-consequence factor in the equation of public's obedience and participation, and therefore as an indicator to the system's accomplishments rate.

\section{Processes, Equipments and Infrastructures}

\subsection{MSW properties and generation patterns}

Accra is important administrative, commercial and industrial centres in Ghana. Besides their resident populations, they also attract traders, visitors and tourists from all parts of the country and beyond. The production and consumption activities of the resident generate enormous quantities of solid waste on a daily basis. A number of factors are contributing to the growing volumes of solid waste in these cities. Over the years, rapid urbanization has been accompanied by expansion of the urban economy, rising incomes among the population and increased production and consumption of products. These factors have contributed to the growing volumes of solid waste in the cities. Municipal authorities predicted an increment of 190 tons of daily-generated waste, from the year of 2009 until 2020 (Accra Municipal Assembly). So far, the available studies referring to waste generation characteristics are somehow limited (in quantity and quality) and out-dated. Accurate and reliable data is an important resource in any area that requires planning and organisation including waste management. Therefore, any city that is unable to continuously generate accurate data on the waste situation will be unable to plan and execute an effective waste management project. 


\subsection{Collection and public cleansing}

MSW collection system in Accra City has a coverage rate of just about 80-85\% in the city (Accra Municipal assembly). To ensure the collection of all waste generated in the city, guidelines have been provided to residents of the city on how to handle the various types of waste that are generated. The organisation of solid waste management in any city requires an adequate supply of logistics including vehicles and tools for waste collection and transportation, and to provide a sustainable waste management service, there is also the need to maintain a back up of equipment and ready availability of spare parts for fleet maintenance.

The study found that inadequate logistics hamper the organisation of waste management in Accra city. Interviews with stakeholders in the waste sector and field observations conducted in the city showed that the municipal authorities lack the logistics required for the collection and transportation of solid waste to disposal sites and for the maintenance of the disposal sites. Waste collection in Accra cities is a major problem due to the hazards to public health and the impacts on environment. Commercial wastes are mixed in most cases with the domestic wastes transported by trucks to the waste dumping sites without any protection measures. Problems arise as the households and the commercial facilities do not provide own containers or bins to collect and store the waste temporary. The waste is dumped daily in the street either in plastic bags or even without any container. The available equipment is insufficient to fulfil the requirements. The habits of the inhabitants and the commercial facilities together with the working time of public services increase the problem with the result that the alleys and streets are polluted with garbage. This has negative impacts not only on the living conditions in the City but also on the attractiveness for tourism and business activities. Collection and transport vehicles owned by the municipal authorities are old, and intensively used and on the top of that do not benefit from regular maintenance. Public waste containers also present obsolete features and their placement in the fixed points, sometimes hinders the traffic (Accra Municipal Assembly). From the public questionnaire and Interviews with stakeholders in the waste sector and field observations conducted in the city showed that the municipal authorities lack the logistics required (containers-vehicles) for the collection and transportation of solid waste to disposal site. These equipments are urgent need to have significant improvements in MSW collection and public cleaning services.

My observations in several low-income communities in Accra city and interactions with residents confirmed the equipment problem. The authorities were neither able to supply enough waste containers for waste disposal in the communities nor able to meet the schedule for their removal and replacement. It was also observed that when the containers get filled or are removed without immediate replacement, the residents dump their waste on the ground that results in waste accumulation at the container sites.

\subsection{MSW processing and treatment}

2.3.1 Sorting waste for recycling activities: In general there are relatively low recycling efforts practiced in Accra city. However, recycling represents an important business with high development potential in the future. It is common to see underprivileged persons scavenging through the solid waste containers in Accra. The scavengers are 
mostly searching for cardboard, tins and plastic bottles and containers. Usually there are middlemen that sell the recycled materials to factories. Furthermore, sorting of recyclables by scavengers at the landfill site is a common practice. This indicates that there exists a market for such materials. The public questionnaire survey gave an indication that the main reasons might be because the public do not have any interest in participate or because they do not know how to participate and where to find recyclable waste collection points. Either ways, there is a gap concerning the awareness of recycling significance and shortage of comprehensive recycling related initiatives.

2.3.2 Composting: Composting is the option that, with few exceptions, best fits within the limited resources available in developing countries [1]. There is no awareness in the country concerning composting. Compositing minimizes emissions produced from waste under sanitary landfill conditions. Utilization of compost will decrease the expenditures on importing the fertilizers. Despite the significant benefits of composting, but until now there is not composting project exist in Ghana.

2.3.3 Applied final disposal method: Landfilling is one of the simplest and cheapest method regarding disposing of waste [2] therefore, waste can be decreased by the total volumes of MSW being produced [3, 4]. Among the major cities in Ghana, Accra has the most engineered landfill now, which used to be a heavily polluting dumpsite before its rehabilitation. It has not a composite liner but a single natural clayey layer, which achieved a permeability of $1 \times 10$ $9 \mathrm{~m} / \mathrm{sec}$. After collecting the solid waste from various regions and sources of Ghana city, the collection vehicles haul the waste to the landfill, which is located 5 to $6 \mathrm{~km}$ away from the city centre. The operation of the landfill site is proceeding by the private sector under the supervision of the municipality of Accra. It serves Accra city and other smaller municipalities in the area. The amount of waste transported to the landfill is about 410,000 t/year (1,100 t/d). The total area of the site is approximately 36 ha- 16 ha in operation. Most landfills are not regulated and expose workers to hazardous condition.

\section{Public Awareness and Participation Indicators in Accra City}

Along with the data already presented, the results from the public questionnaire (106 responders) done in Accra City is a major influence and supportive tool in the analysis and proposed solutions for the present MSWM situation.

\subsection{Public awareness about MSWM}

When asked about their knowledge level about MSW matters 61 responders considered it medium, 38 responders considered it low and 7 responders considered it high. When asked the source of the knowledge, $43 \%$ of the answers pointed that it was from school, $37 \%$ from media sources, $11 \%$ from authorities and $9 \%$ of the answers mentioned friends as a source. Related to the knowledge of any MSWM service 55 responders said that have no knowledge, and 51 responders answered positively but only 39 responders could give examples of it. 


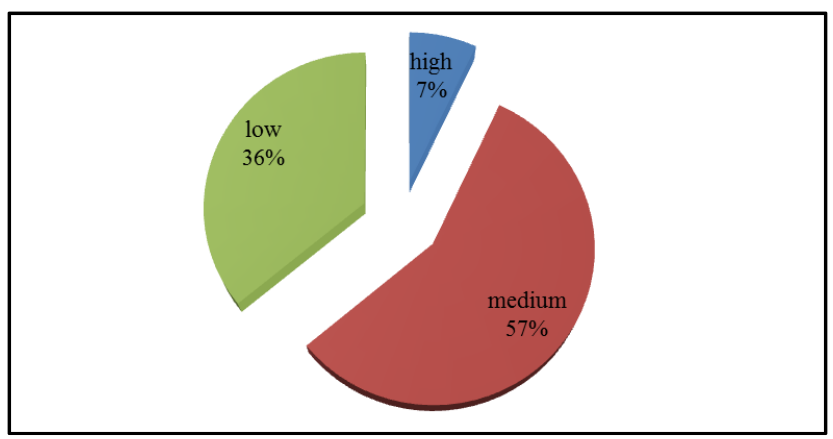

Figure 1: Level of knowledge about MSW matters.

Figure 2 presents the results from the question in relation to consequences of a deficient MSWM system, the percentage of each type of answer is stratified as follows: causes presence of diseases (36\%); bad smell (34\%); sanitation and environmental issues (17\%); compromised aesthetics (13\%).

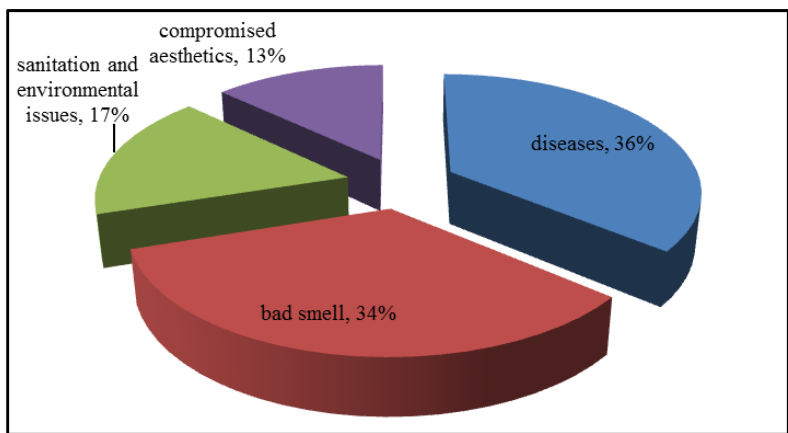

Figure 2: Consequences of a deficient MSWM system.

The last question about the public awareness was related to the knowledge of municipality rule/policy and it is illustrated in Figure 3 that, 85 responders do not know any rule while 21 responders know some rules regarding SWM matters. But most of responders know rules related to the time for waste deposition in collective containers.

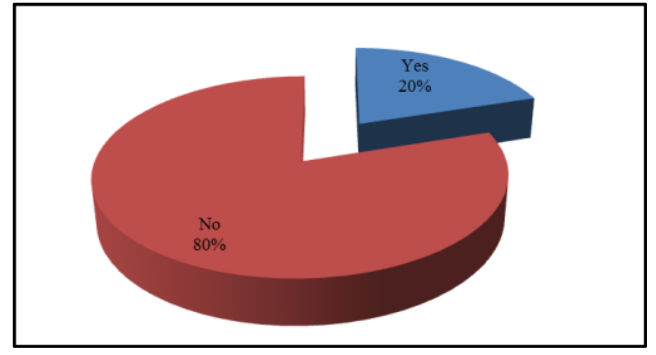

Figure 3: Knowledge about any existent rule.

The lack of environmental awareness among Ghanaians can be attributed to the government's low commitment to environmental issues and the waste problem in particular which makes it fail to sensitise the populace to environmental sanitation and the need to live in harmony with the environment. This is because there is no visible evidence of government effort to sensitise the population on the need for sound waste disposal practices and living 
in harmony with the environment. The investigations conducted for this study indicate that enormous opportunities exist for the government to educate the people on environmental sanitation and waste handling including the electronic and print media. Considering the wide spatial coverage of both the electronic and print media in Ghana, government sponsored educational programmes on environmental sanitation or waste disposal through the media can have far reaching impacts on the population. In Accra city, municipal waste departments were convinced of the usefulness of the media in educating the public. However, the local governments lack the funds to sponsor media programmes and so look up to the central government to do this.

\subsection{Public participation in MSWM related activities}

Availability to participate in MSW related activities was $71 \%$ positive and $29 \%$ negative. Major reason for the negative answer is the time availability limitation. About waste recycling, just 20 responders, out of 106 responders, recycle their waste; the cause for the low recycling number varies from time availability (around 36\%), lack of knowledge about the city current recycling process (around 19\%), no necessity to recycle (around 24\%) and no interest in it (around 21\%).

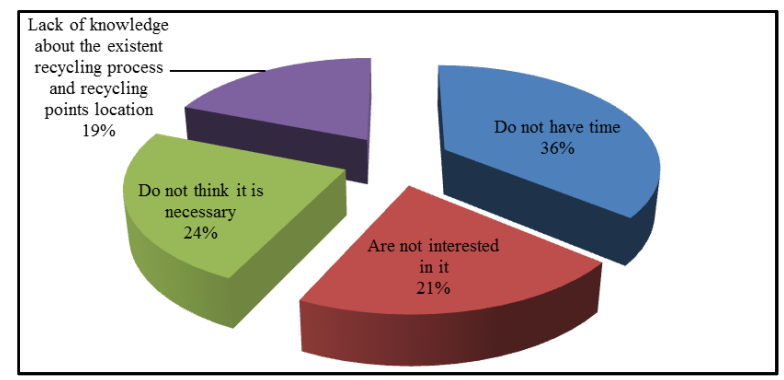

Figure 4: Reasons for not recycle.

Responder's main recommendations for the improvement of Accra City MSWM system were linked to the necessity to improve waste collection services (29\%); increase the number of available public containers (21\%); improve the overall cleaning of the city (19\%) and the necessity to improve the methods used to treat and final dispose the MSW $(16 \%)$; increase the number of workers $(15 \%)$.

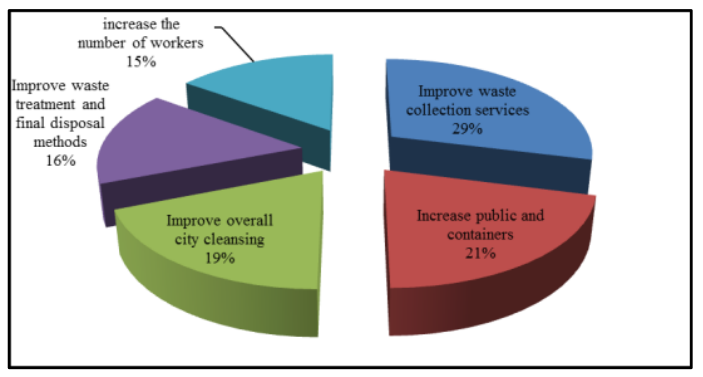

Figure 5: Responders recommendations for MSWM system improvement.

Public participation in MSWM related activities depend on two main reasons, the existence of widespread activities and the willingness of the public to participate in them. Citizens' aspirations include the desire to live in a place with 
good hygienic condition and free of diseases. Responses indicate that there is an open door to be explored and developing initiatives or measures that require public participation, might flourish, if taking in high consideration public well being factors. Moreover, lack of awareness about MSW matters, must also be considered as a direct cause of low participation.

\section{The Lessons Learned from Chongqing city MSWM System}

According to previous studies about Chongqing city MSWM system and the developed theoretical background, it is possible to identify the following set of the lessons learned to achieve improvements for Accra City MSWM system.

\subsection{Authorities and institutional performance}

- A realistic policy framework must be formulated to guide urban sector institutions as well as provide them adequate legal support to enforce their mandates.

- There is the need to strengthen and resource urban management agencies to enable them carry out their mandates of planning and managing cities in the country. These institutions need to be well resourced with operational funds, logistics and qualified personnel to enable them to discharge their duties creditably.

- National and municipal governments in Ghana must also commit themselves to improving the conditions of service in the waste and sanitation sub-sectors to make jobs there attractive to both skilled and unskilled personnel.

- Political commitment to waste management should also include active public education on environmental sanitation and waste disposal and the inclusion of environmental education in the country's educational curriculum.

\subsection{Processes, equipments and infrastructures}

\subsubsection{MSW properties and generation patterns:}

- There is the need to gather accurate data on such topics as the quantities and types of waste being generated in the cities, their characteristics. The environmental protection agencies create a database on waste to assist municipal authorities undertake research to facilitate waste planning and management.

- Accurate data on waste generation and composition would be useful in determining appropriate strategies for waste management. The preponderance of organic materials, and to some extent, recyclables in the municipal waste streams, for instance, would suggest that composting and recycling are both appropriate methods of waste management for the bulk of municipal waste.

- In situations where municipal governments lack the capacity to undertake the necessary research to generate waste data, qualified researchers can be recruited from the universities and other research organisations to carry out the research and assist in the planning and implementation of waste management operations. There will also be the need to identify all stakeholders in the waste sector including waste producers, those who provide (formal and informal) waste collection services, waste pickers and recyclers. 


\subsection{Collection and public cleansing}

- Solving the solid waste problem will also require massive investment in equipment and logistics for waste management operations. Adequate investment therefore has to be made in the logistics for waste management including collection trucks and containers. At the same time, the private waste companies must be supported to acquire adequate equipment and other necessary resources to enable them to discharge their duties effectively.

- In order to deal with the problem of street litter, it is hereby recommended that more bins be provided and placed at close intervals in all busy commercial areas and along all major streets in the cities to encourage the floating population to dispose of waste properly and avoid littering the streets. Alongside this, existing waste disposal by-laws should be strictly enforced to deter people from indiscriminate disposal.

- Elaborate an efficient operations monitoring and control system.

- Study the viability for adoption of transfer station(s) as part of a plan for waste treatment and final disposal alternatives.

\subsection{Processing and treatment of MSW}

All waste producers such as households, businesses and institutions should be enlightened on the merits of, and encouraged to practice waste prevention, waste reduction and re-use while measures are instituted to promote recycling, composting. In particular, since the bulk of solid waste generated in the country consists of compostable organic materials, a successful composting project can greatly reduce the amount of solid waste going for land filling and reduce the need for landfill space. The price of compost manure could also be subsidised and kept low to make it affordable to farmers. Even if the sale of compost fails to yield adequate funds to sustain the operation of compost plants, municipal authorities have to accept the fact that the cost of solid waste management can only be minimised and it is highly unlikely that waste can ever yield a profit. After all, solid waste management remains an essential municipal service that aims to protect public health and the environment and should therefore not be treated as a moneymaking venture.

Create legal, financial and supporting environment to incentive more composting initiatives, paying special attention to small scale and community ones, for the reason that this type of initiative, if successfully implemented, creates an inner growth and development of the targeted community and triggers the emerging of similar initiatives.

- To solve the problem of residents mixing organic waste with other waste types, waste producers can be encouraged or even mandated to separate 'compostable' waste materials from recyclables to facilitate material collection for composting.

- Create a proper environment for the development of local recycling industry and explore other overseas markets.

- Implement public awareness rise actions-citizens must first understand the importance of recycling, before put in practice this activity. 
- Consider turning waste scavengers into formal recycling agents, opening a win-win possibility: meaning improvement of the sanitation conditions and social disparity issues, as well as reduction of urban poverty.

- Ease the process of recyclables collection: availability of selective containers with simple and easy to understand instructions to dispose the recyclables in the solid waste selective containers; and existence of accessible and several recycling points.

- There is no MSW incineration facility in Ghana, the main reason for that, the massive required investment needed (in infrastructures, personnel, and equipment, operation and pollution control devices) to employ incineration activities.

\subsection{Applied final disposal methods}

- In fact, there is the need to move away from waste disposal in unmanaged dumps, and to the construction of modern landfills designed to control leachate flow and harvest landfill gas (methane) for energy production. These landfills can be supplemented with recycling and composting all of which can generate additional revenue to fund waste management operations.

- The health implications of people living close to these facilities, it would be helpful for the authorities to site future waste disposal facilities in uninhabited areas far from the cities. Boundaries should then be created around these sites and monitored to prevent people from settling near the facilities. Undoubtedly, siting waste disposal facilities at considerable distances from cities will increase haulage distances and hence the operation costs of waste management. The advantage in this, however, will be the prevention of community pollution.

- Apply sustainable and safe possibilities for open dumpsite future use, such as: methane recovery or site requalification.

- Design new MSW disposal facility that fits the waste characteristics and are technical, socio-economic and environmental sound.

4.6 Public awareness and participation

- Build up a system in which the communication and information flow among all system stakeholders efficiently work, especially for the major MSW generators, by massive publicizing the existent rules and guidelines to be followed and creating more interaction opportunities between the authorities, generators and other major stakeholders.

- Municipal governments must encourage the people to get Knowledge in field environmental sanitation and proper waste management practices such as reuse, recycling, waste prevention and proper waste disposal. This would be a practical way of actualizing the popular adage that 'cleanliness is next to Godliness'. Besides, the media, including the numerous radio stations, television and newspapers should be used to raise awareness among the general public on the importance of maintaining a clean and healthy environment. 


\section{Opportunities and Perspectives for Accra City MSWM System's Improvement}

In the future, to meet the needs of an integrated solid waste management system, the following aspects should be improved.

\subsection{Improved funding and equipment for waste management}

In order to improve waste management in Ghana cities, the perennial financial crisis that characterises the waste sector also needs to be addressed. In this regard, there is a need for the central government to greatly improve its allocations to municipal governments and also make these allocations more regular to meet the operational costs of waste management. At the same time, the municipal governments must be supported to improve revenue mobilisation from local sources. Attracting qualified finance can do this and accounting staff that will help identify additional sources of funds such as taxes on properties and business, and also improve the financial management practices of the assemblies by plugging leakages and stemming corruption. Solving the solid waste problem in Ghana cities will also require massive investment in equipment and logistics for waste management operations. Adequate investment therefore has to be made in the logistics for waste management including collection trucks and containers, and also in equipment for the maintenance of disposal sites. The waste management departments of the various cities should also be supported to establish well-equipped garages with the necessary spare parts, and to recruit well-qualified engineers and supporting mechanics to maintain the equipment. Chongqing government built and improved waste collection facilities and transfer stations in both urban and rural area. These stations are generally well maintained and use standard features and methods such as waste compaction [5]. Nowadays, waste collection equipments well equipped, the waste containers were re-designed to selective containers and suitable vehicles (with compaction system) are being used. The vehicles are also equipped with geographic position system (GPS) devices.

\subsection{Political commitment to waste management}

The study has shown that both national and local governments in Ghana have low level of commitment to waste management and this proves to be the root cause of the waste problem in the country's cities. A major part of the solution lies in the enactment of a national waste policy to guide the conduct of waste management. A realistic policy framework must be formulated to guide urban sector institutions as well as provide them adequate legal support to enforce their mandates. Furthermore, there is the need to strengthen and resource urban management agencies to enable them carry out their mandates of planning and managing cities in the country. These institutions need to be well resourced with operational funds, logistics and qualified personnel to enable them to discharge their duties creditably. To tackle the waste problem effectively, national and municipal governments in Ghana must also commit themselves to improving the conditions of service in the waste and sanitation sub-sectors to make jobs there attractive to both skilled and unskilled personnel. Besides, political commitment to waste management should also include active public education on environmental sanitation and waste disposal and the inclusion of environmental education in the country's educational curriculum. 
In Chongqing, the responsibility in managing MSW activities remains with the Chongqing Municipal Administrative Committee and it has, in its turn, other subordinate institutions with different specific objectives related to the whole MSWM system. A non-centralized type of management, like the one currently adopted in Chongqing City, if successfully implemented, may give enough space and work autonomy to each one of the institutions in order to concentrate all effort and focus on their own specific objectives; supporting each other when necessary, but at the same time rendering accounts to the main institution independently. Also, it can allow a relatively simple control process of the work progress within all MSWM system components.

\subsection{Adopting integrated solid waste management}

It recommended that integrated solid waste management (ISWM) be adopted as a guiding framework within which to conduct the business of waste management in the country. In this regard, municipal authorities in Ghana should prioritise the various strategies of solid waste management in the order presented by the waste hierarchy. All waste producers such as households, businesses and institutions should be enlightened on the merits of, and encouraged to practice waste prevention, waste reduction and re-use while measures are instituted to promote recycling, composting and incineration for energy with waste disposal being the last options. In particular, since the bulk of solid waste generated in the country consists of compostable organic materials, a successful composting project can greatly reduce the amount of solid waste going for land filling and reduce the need for landfill space. In fact, there is the need to move away from waste disposal in unmanaged dumps, and to the construction of modern landfills designed to control leachate flow and harvest landfill gas (methane) for energy production.

To solve the problem of residents mixing organic waste with other waste types, waste producers can be encouraged or even mandated to separate 'compostable' waste materials from recyclables to facilitate material collection for composting. The compost might also be better accepted if farmers are encouraged to use it on cereal crops that get processed before consumption instead of using it in the cultivation of vegetables. The price of compost manure could also be subsidised and kept low to make it affordable to farmers. Even if the sale of compost fails to yield adequate funds to sustain the operation of compost plants, municipal authorities have to accept the fact that the cost of solid waste management can only be minimised. After all, solid waste management remains an essential municipal service that aims to protect public health and the environment and should therefore not be treated as a moneymaking venture.

Changshengqiao Sanitary Landfill, is the first standard sanitary landfill in Chongqing and it employs an engineered method of disposing solid wastes on land in a manner that minimizes environmental hazards by spreading the solid waste in thin layers, compacting the solid wastes to the smallest practical volume and applying a cover at the end of the operating day [6]. The sites that once were simple landfills are now being gradually remediated [5]. An integrated disposal plant including incineration, landfill and composting is implemented, for Chongqing City, in the year of 2012 [5]. 


\subsection{Generating data for planning waste management}

The lack of data on the waste situations in Ghana cities is a constraint to the planning and organisation of waste management operations. To overcome this problem, there is the need to gather accurate data on such topics as the quantities and types of waste being generated in the cities, their characteristics, as well as the waste disposal practices among the population. Accurate data on waste generation and composition, for example, would be useful in determining appropriate strategies for waste management. The preponderance of organic materials, and to some extent, recyclables in the municipal waste streams, for instance, would suggest that composting and recycling are both appropriate methods of waste management for the bulk of municipal waste in Ghana. To promote these strategies of waste management, however, the current practice of mixed-waste disposal must be discouraged and households must be encouraged to separate the different waste types. In situations where municipal governments lack the capacity to undertake the necessary research to generate waste data, qualified researchers can be recruited from the universities and other research organisations to carry out the research and assist in the planning and implementation of waste management operations. Waste quantity and composition values in Chongqing City are currently acquired from sampling points located in MSW treatment plants and in this process it is taking in consideration the fact that waste scavenging is present in the waste stream. In addition, it is part of the authority's future plans to promote source separation and waste reduction at generation [7-12].

\subsection{Public education on environmental sanitation}

The poor waste management culture among Ghanaians can be addressed through public education on environmental sanitation in general and waste disposal in particular. This can be achieved through such avenues as schools, churches/mosques and the media. Environmental sanitation should be made an integral part of the basic education curriculum, while institutions of higher learning such as the universities and polytechnics should be encouraged to introduce programmes on environmental management, including courses on waste management, to train qualified personnel for the sector. The fact that most Ghanaians are either Muslims or Christians also makes religious organisations important avenues for environmental education. Municipal governments must, therefore, build partnerships with religious leaders and encourage them to educate their members on environmental sanitation and proper waste management practices such as reuse, recycling, waste prevention and proper waste disposal. This would be a practical way of actualising the popular adage that 'cleanliness is next to Godliness'. Besides, the media, including the numerous radio stations, television and newspapers should be used to raise awareness among the general public on the importance of maintaining a clean and healthy environment [13-16].

\subsection{Strict enforcement of regulations on waste management}

The study has shown that the public has a poor waste handling culture that exacerbates the waste disposal problem in the country (Ghana). To curtail this negative public attitude, the municipal authorities must strictly enforce existing by-laws on waste disposal including littering. Once environmental education has been carried out and waste disposal services are extended to all communities including litter bins at all vantage point within the cities, there will be no excuse for persons who engage in improper waste disposal practices and the law should be made to take its 
course to bring any offenders to book. Prescribed penalties for waste disposal offences should include court fines, orders to clean up the streets and even imprisonment depending on the gravity of the offence committed. To facilitate the enforcement of the waste disposal by-laws, however, municipalities will have to be supported to recruit enough environmental sanitation guards to monitor waste handling by the public. They will also need the support of the law enforcing agencies such as the police and the courts to help bring offenders to book. These measures will go a long way to improve the waste disposal situation in most cities in Ghana.

\section{Conclusion}

For certain goals set by Chongqing Municipal Government, the monitoring, control and results evaluation is somehow strict. As an example, in case refuse fee collection goals are not achieved, the related personnel may be sanctioned by having salary cuts or by being fired. This type of approach may stimulate and input a dynamic in the several system departments, increase the rate of positive results, and can even create an encouraging and competitive environment among the workers and different related institutions.

\section{References}

1. UNEP (United Nations Environment Programme). Principles of solid waste management. Solid Waste Management (2005): 1-8.

2. Taylor R, Allen A. Waste disposal and landfill: Potential hazards and information needs (2003).

3. Allen A. Attenuation landfills the future in landfilling (2000).

4. Lebersorger PBAS. Forecasting municipal solid waste generation for urban and rural regions XII international waste management and landfill symposium Sardinia, Italy (2009).

5. Wang L Pei, Huang TC. Yuan H. Management of municipal solid waste in the Three Gorges region. Waste Management 29 (2009): 2203-2208.

6. Yuan H, Wang F, Hu G. Urban solid waste management in Chongqing: Challenges and opportunities. Waste Management 26 (2006): 1052-1062.

7. Environmental Protection Agency (Ghana) for Ministry of Works and Housing Korle Lagoon Ecological Restoration, Environment and Social Impact Statement. Final Report. Accra, Ghana (2001).

8. Environmental Protection Agency. Ghana's State of the Environment Report (2002).

9. United Nations Environment Programme (UNEP). Solid Waste Management1 (2005).

10. Al-Yousfi AB. Environmentally Sound Technologies (EST) for Designing and Operating Solid Wastes Landfills. United Nations Environment Programme (UNEP), Regional Office for West Asia (ROWA), Proceedings of International Conference on Wastes Management and Pests Control, Muscat MunicipalityOman (2003).

11. Kanbour F. General Status on Urban Waste Management in West Asia, Regional Workshop. United Nations Environment Programme (UNEP), Regional Office for West Asia (ROWA) (2010). 
12. Al-Yousfi AB. Regional Perspectives of Hazardous Waste Management in Developing Countries. United Nations Environment Programme (UNEP), Regional Office for West Asia (ROWA), Proceedings of Oman International Conference on Wastes Management (2002).

13. United Nations Environmental Programme (UNEP). Waste Management Planning: An Environmentally Sound Approach for Sustainable Urban Waste Management. GDRC (2005).

14. United Nations Programme for Environmental Protection (UNEP). Integrated Waste Management Scoreboard-A tool to measure performance in municipal solid waste management (2005).

15. United Nations Programme for Environmental Protection (UNEP). Solid Waste Management (2005).

16. United States Environmental Protection Agency Office of Solid Waste (2008).

Citation: Sylvia Adipah. Challenges and Improvement Opportunities for Accra City MSWM System. Journal of Environmental Science and Public Health 3 (2019): 133-146.

This article is an open access article distributed under the terms and conditions of the Creative Commons Attribution (CC-BY) license 4.0 